\title{
Measurement of the microwave effective permittivity in tensile-strained polyvinylidene difluoride trifluoroethylene filled with graphene
}

B. J. P. Adohi, V. Laur, B. Haidar, and C. Brosseau

Citation: Appl. Phys. Lett. 104, 082902 (2014); doi: 10.1063/1.4866419

View online: https://doi.org/10.1063/1.4866419

View Table of Contents: http://aip.scitation.org/toc/apl/104/8

Published by the American Institute of Physics

\section{Articles you may be interested in}

Microwave and mechanical properties of quartz/graphene-based polymer nanocomposites

Applied Physics Letters 102, 072903 (2013); 10.1063/1.4793411

Characterization of CVD graphene permittivity and conductivity in micro-/millimeter wave frequency range AlP Advances 6, 095014 (2016); 10.1063/1.4963140

Graphene and temperature controlled butterfly shape in permittivity-field loops of ferroelectric polymer nanocomposites

Applied Physics Letters 110, 022902 (2017); 10.1063/1.4973810

Microwave absorption properties of the carbon-coated nickel nanocapsules

Applied Physics Letters 89, 053115 (2006); 10.1063/1.2236965

Fabrication and evaluation of thin layer PVDF composites using MWCNT reinforcement: Mechanical, electrical and enhanced electromagnetic interference shielding properties

AIP Advances 6, 065107 (2016); 10.1063/1.4953810

Meta-atom microfluidic sensor for measurement of dielectric properties of liquids

Journal of Applied Physics 121, 094506 (2017); 10.1063/1.4978012

\section{PHYSICS TODAY}

MANAGER'S GUIDE

Accelerate R\&D with

Multiphysics Simulation
READ NOW

PRESENTED BY

И $\subset$ M 


\title{
Measurement of the microwave effective permittivity in tensile-strained polyvinylidene difluoride trifluoroethylene filled with graphene
}

\author{
B. J. P. Adohi, ${ }^{1,2}$ V. Laur, ${ }^{1}$ B. Haidar, ${ }^{3}$ and C. Brosseau ${ }^{1, a)}$ \\ ${ }^{1}$ Lab-STICC, Université de Brest, CS 93837, 6 avenue Le Gorgeu, 29238 Brest Cedex 3, France \\ ${ }^{2}$ Laboratoire de Physique de l'Atmosphère et de Mécanique des Fluides, UFR-SSMT, \\ Université Félix Houphouët-Boigny de Cocody, 22 BP 582 Abidjan 22, Ivory Coast \\ ${ }^{3}$ Institut de Science des Matériaux de Mulhouse, 15 rue Jean Starcky, BP 2488, \\ 68057 Mulhouse Cedex, France
}

(Received 17 January 2014; accepted 7 February 2014; published online 24 February 2014)

\begin{abstract}
We report an interesting effect in the form of a rise (up to 13\%) in the permittivity of graphene (GE) filled polyvinylidene difluoride trifluoroethylene (P(VDF-TrFE)) subjected to a small uniaxial deformation (up to $7 \%$ in the principal direction). Our findings differ from GE-PVDF homopolymer samples that show a decrease of permittivity upon elongation. We argue that the VDF content which controls the spontaneous polarization has a profound effect on the charge storage through the addition of interface density by the GE phase. (O 2014 AIP Publishing LLC.

[http://dx.doi.org/10.1063/1.4866419]
\end{abstract}

The ability to manipulate electromagnetic wave is essential in the development of many technological devices such as sensors, waveguides, and actuators. In recent years, many methods have been developed, and several nanostructures and complex compounds are used intensely to control their electromagnetic properties by means of a modest electric field, e.g., metamaterials ${ }^{1,2}$ and multiferroic materials., Due to its unique electronic and mechanical properties, graphene (GE), an atomic layer of $\mathrm{sp}^{2}$-hybridized carbon with a two-dimensional honeycomb lattice, ${ }^{5,6}$ can be the key element in promising applications. Whereas, extensive work has been focused on its electronic behavior, more and more proposed devices, such as plasmonic waveguides ${ }^{7}$ and rectennas, ${ }^{8}$ rely on its terahertz and microwave properties.

On the other hand, a great deal of current research focuses on plastic electronics. ${ }^{9,10}$ In some respects, soft materials filled by GE are ideally suited for electronic applications because of potentially interesting emergent interfacial phenomena between GE sheets and polymer chains. Experimental progress on GE based polymer nanocomposites has steadily advanced recently due largely to the control of the elasticity network during their fabrication. ${ }^{11-20}$ One reason that makes these systems, so appealing is the fact that the processing may modify the structural and dielectric properties, particularly at the filler particles-polymer interfaces, in a manner that is difficult to characterize and control. With incorporation of GE (sheets with thickness $10-20 \mathrm{~nm}$ and average lateral size $200 \mu \mathrm{m}$ ) in amorphous styrene butadiene rubber (SBR) with quartz grains on the order of micrometers in size, a significant increase (up to $25 \%$ ) occurs in the effective microwave permittivity of these hybridized nanocomposites comprising both quartz and GE compared to the nanocomposites with quartz only. ${ }^{16}$ By examining the mechanical response, it was shown that the elasticity network of SBR polymer chains is significantly affected in the rubbery state by filling SBR with GE and quartz particles. We argued that the coating of quartz grains by GE sheets is the most

${ }^{\text {a)} E l e c t r o n i c ~ m a i l: ~ b r o s s e a u @ u n i v-b r e s t . f r ~}$ likely origin of this synergetic effect. ${ }^{16}$ The electromagnetic interference shielding performance of other polymer matrices such as polyurethane ${ }^{21}$ and poly(dimethyl siloxane) $)^{22}$ filled with GE have been also investigated recently.

Nevertheless, to realize their full potential, GE-based multifunctional soft materials are highly desirable. The imprecise nature of our understanding may, in part, be related to the complexity associated with the interplay of inhomogeneous strain at the polymer interfaces with the electromagnetic wave transport. Further insights are equally important from an engineering perspective, as the coexistence of both ferroelectricity and magnetism with GE decorated with maghemite nanoparticles can offer a huge potential for unusual manipulation of electromagnetic waves. ${ }^{23}$

Given this motivation, the work presented in this Letter aims at characterizing the mechanical and microwave properties of a series of polyvinylidene difluoride trifluoroethylene (P(VDF-TrFE))-GE nanocomposites. The archetypal ferroelectric PVDF is widely used in piezoelectric and electrostrictive applications, but it is also studied as a model polymeric material because samples filled with GE sheets are both easily produced and manipulated and relatively rigid, and it is a comprehensively studied polymer with well-known bulk material properties. Despite the extensive experimental work on PVDF and filled PVDF, far less attention has been paid to $\mathrm{P}(\mathrm{VDF}-\mathrm{TrFE})$ filled with GE. Trifluoroethylene (TrFE) is like vinylidene fluoride (VF) except that one of the hydrogens is replaced by an additional fluoride atom, thus, when TrFE is copolymerized with VF, it essentially acts as a source of defect groups, so that the polymer spontaneously forms the $\beta$ phase regardless of the processing method. Two aspects of this research field are addressed in this Letter via detailed microwave permittivity measurements. First, we present the microwave permittivity spectra of GE filled $\mathrm{P}(\mathrm{VDF}-\mathrm{TrFE})$ samples for three copolymer compositions. The effective permittivity measurements indicate a large increase of the (real part) of the effective permittivity of samples with $1 \mathrm{phr}$ GE loading, depending on the copolymer composition. Second, we measure the effective permittivity 
of the samples under elongation for small deformation. While the permittivity change versus strain has the expected trend for the PVDF homopolymer filled with GE, ${ }^{16}$ the permittivity of $\mathrm{P}(\mathrm{VDF}-\mathrm{TrFE})$-GE composites gets larger as the elongation ratio increases in sharp contrast with earlier observations on a range of filled polymers. The physical reason behind these observed characteristics is ascribed to the interfacial polarization charges, revealing signature of the vinylidene fluoride (VDF) content which controls the spontaneous microwave permittivity.

We present studies of samples prepared using melt mechanical mixing of semicrystalline P(VDF-TrFE) copolymers obtained from Piezotech (Arkema) or PVDF homopolymer purchased from Goodfellow, and GE in platelet form was obtained from Angstron Materials Inc., USA. A series of samples was fabricated as described in a previous study. ${ }^{24}$ Random copolymers of VDF and TrFE with compositions $50 / 50,77 / 23$, and $100 / 0$ in weight $\%(\mathrm{VDF} / \mathrm{TrFE})$ were used. The GE loading was set to $1 \mathrm{phr}$. The microstructure investigation draws upon several complimentary experimental techniques: Transmission electron microscopy (TEM) and X-ray diffraction (XRD) with $\mathrm{Cu} \mathrm{K}_{\alpha}$ radiation (X-ray wavelength $=0.154 \mathrm{~nm}$ ). XRD (Empyrean, Panalytical) $\theta-2 \theta$ scans (Fig. 1(a)) confirmed that the composite contain only $\mathrm{P}(\mathrm{VDF}-\mathrm{TrFE})$ and GE (sharp reflection at $2 \theta=26.2^{\circ} \pm 0.1^{\circ}$ due to the graphitic interlayers (002)) phases. Cryofractured surfaces of composite were observed by TEM (JEOL, JEM1400 operating at $120 \mathrm{kV}$ ) to examine the GE dispersion in the polymer matrix. Here, as a representative example, we present in Fig. 1(b) a TEM micrograph of a microtomed thin section of a PVDF-GE sample on a holey carbon-covered copper grid. The bright areas are GE regions of relatively high electron transparency embedded in the amorphous polymer background. The average size for the GE sheets was found to be several hundreds of nm.

Diagnosing the material properties using differential scanning calorimetry (DSC) is important to detect thermal transitions and characterize crystalline order. DSC (Mettler Toledo DSC-1) measurements in the temperature range from -150 to $230^{\circ} \mathrm{C}$ at a heating rate of $10^{\circ} \mathrm{C} / \mathrm{min}$ indicate a glass transition temperature in the range from $-20^{\circ} \mathrm{C}$ to $-30^{\circ} \mathrm{C}$. The Curie temperature $T_{\mathrm{c}}$ and melting point $T_{\mathrm{m}}$ for $\mathrm{P}(\mathrm{VDF}-\mathrm{TrFE})$ copolymers vary with VDF content (Fig. 2(a)). The introduction of GE does not significantly change the melting temperature positions for the two P(VDF-TrFE) copolymers (not shown) suggesting that no more crystallites are being nucleated through the addition of nanoparticles. ${ }^{25}$ Our measurements show a decrease of $T_{\mathrm{c}}$ by a tenth of degrees for a GE loading of $1 \mathrm{phr}$. The degree of crystallinity is estimated from DSC results knowing the heat of fusion of pure crystalline PVDF $\left(104.6 \mathrm{Jg}^{-1}\right){ }^{26}$ e.g., equal to $62 \%$ $(\mathrm{VDF}=77 \%)$. Dynamic mechanical analysis $(\mathrm{DMA})$ of the composite samples was carried out with a DMA instrument (Mettler DMA-861) at a heating rate of $2{ }^{\circ} \mathrm{C} / \mathrm{min}$ from $-150^{\circ} \mathrm{C}$ to $100^{\circ} \mathrm{C}$ and frequency of $10 \mathrm{~Hz}$ by using a shear mode at an oscillation amplitude of $2 \mu \mathrm{m}$. Samples used for DMA are prepared as disks of $1.8 \mathrm{~mm}$ [thickness] $\times 4 \mathrm{~mm}$ [diameter].
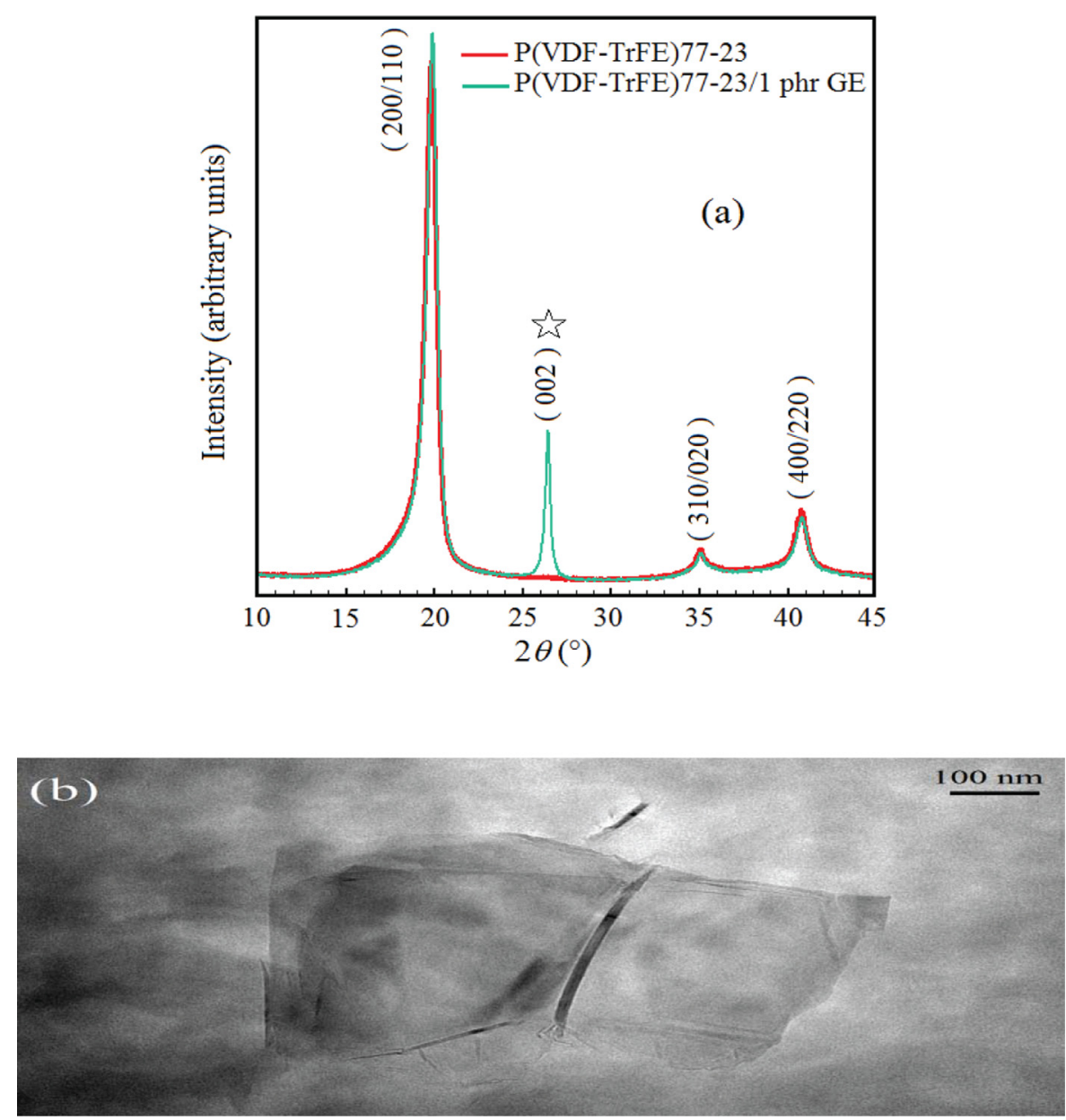

FIG. 1. (a) XRD patterns for samples P(VDF-TrFE)77-23 without (red) or with (green) $1 \mathrm{phr}$ GE as indicated. The star indicates the peak for the GE phase. (b) TEM image of GE sheets in a GE filled PVDF ( $\alpha$ phase) sample. The typical fibrillar microstructure is visible. 

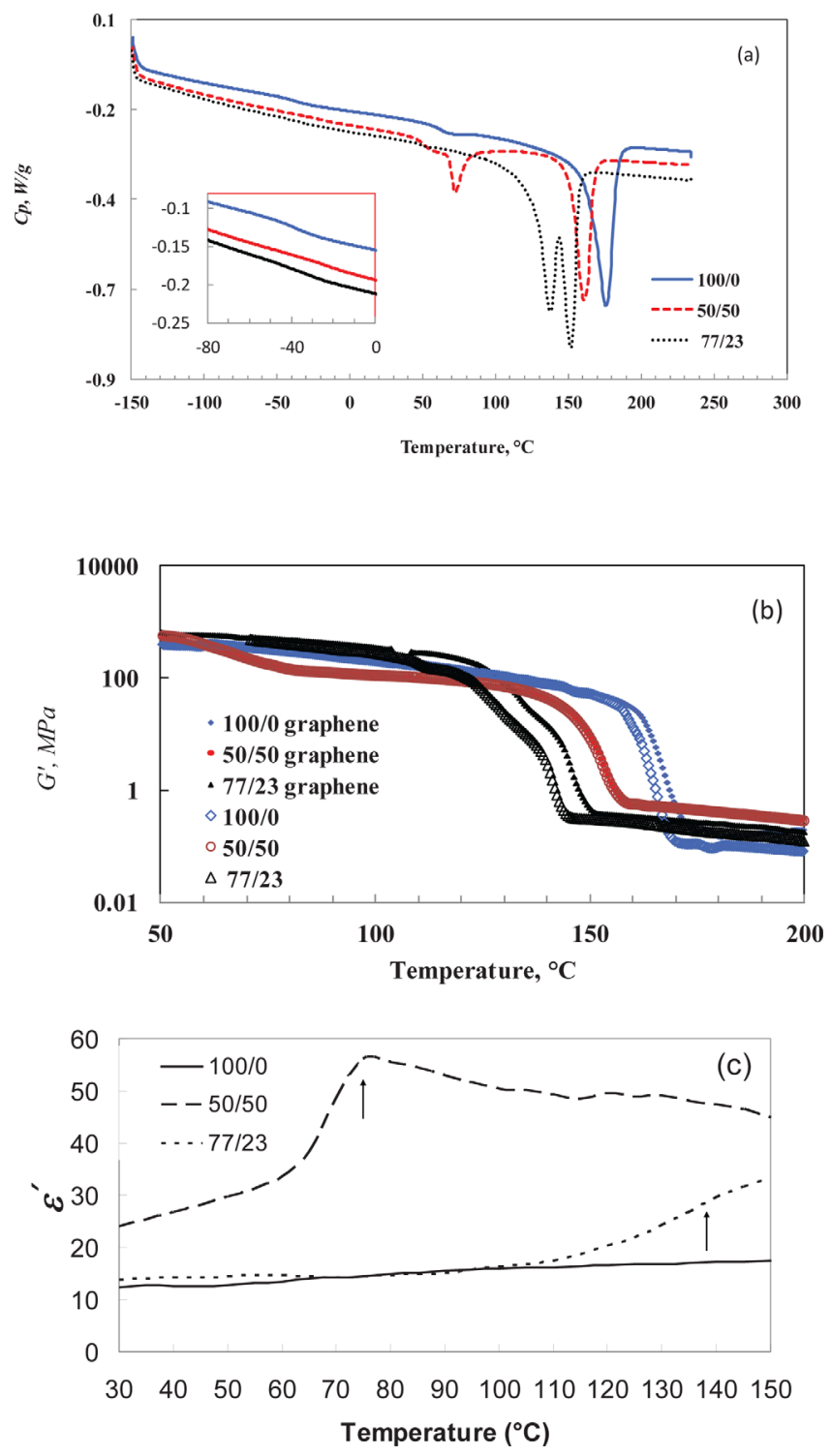

FIG. 2. (a) DSC heating thermograms of the pure P(VDF-TrFE) copolymer. The dashed (respectively, dotted and solid) curve deals with 50/50 (respectively, 77/23 and 100/0) in weight \% (VDF/TrFE) compositions. The homopolymer has a high melting point. For the TrFE copolymers, in addition to the melting points, the Curie transitions are also observable in the DSC traces. The inset is a zoom of the thermogram close to $T_{\mathrm{g}}$. (b) Storage modulus $G^{\prime}$ of the P(VDF-TrFE) copolymer samples without (open symbols) or with (filled symbols) $1 \mathrm{phr}$ GE as a function of temperature measured by DMA. (c) Real part of the effective permittivity $(100 \mathrm{~Hz})$ as a function of temperature of the same samples as in (a). The arrows indicate the Curie transitions.

Figure 2(b) displays the dynamic storage modulus $G^{\prime}$ of the GE-filled samples as a function of temperature. The pure polymer samples are also included for comparison. Incorporating $1 \mathrm{phr} \mathrm{GE}$ in the polymer matrix has for effect to upshift the $G^{\prime}$ vs $T$ curve by $5-10{ }^{\circ} \mathrm{C}$ from that of the unfilled sample, except for the P(VDF-TrFE)50/50. These features are consistent with the addition of a filler to a crystalline polymer. ${ }^{27}$ The values of $T_{\mathrm{m}}$ found for the composite samples are in good agreement with the DSC data. To provide a more complete description of thermal transitions, we have also performed capacitive measurements of the static $(100 \mathrm{~Hz})$ permittivity as a function of temperature using a TF Analyzer 2000-aixACCT test equipment. These data
(Fig. 2(c)) are consistent with previous studies of the crystalline order by our DSC measurements and earlier neutron investigations. $^{25}$ Overall, we underscore that the apparent contrast between the thermal behavior of our samples is related to the VDF content.

Room temperature measurements of the effective (relative) permittivity $\varepsilon=\varepsilon^{\prime}-j \varepsilon^{\prime \prime}$ in the $0.3-6 \mathrm{GHz}$ range under uniaxial stress were carried out using a procedure which is described elsewhere. ${ }^{28}$ Briefly, we obtained $\varepsilon$ from the measurement of the scattering parameters using an Agilent HP8753ES vector network analyzer with SOLT calibration. An error analysis indicates modest uncertainties in $\varepsilon^{\prime}(<5 \%)$ and $\varepsilon^{\prime \prime}(<1 \%)$ for the data. Each experiment was repeated a number of times with different samples to confirm the result. The magnitude of the permittivity was observed to change between repeats by up to $\pm 4 \%$. In the microwave tests reported here, the samples have dimensions $70 \mathrm{~mm}$ [length] $\times 5 \mathrm{~mm}$ [width] $\times 1.6 \mathrm{~mm}$ [thickness]. We observed (not shown) that the two perpendicular directions experience the symmetric contraction by $1 / \sqrt{\lambda}$. and the principal direction is elongated by $\lambda=\ell / \ell_{0}$, where the length $\ell$ of the rectangular-shaped sample is measured with respect to the length the corresponding sample $\ell_{0}$ has initially. From this, we can infer that these variations reflect volume conservation of the polymer sample.

In Fig. 3, we plot the real and imaginary parts of the effective permittivity of our all samples as a function of frequency and at ambient conditions. There are three distinct features to be pointed out at first glance: (i) The $\varepsilon^{\prime}$ data clearly indicate that PVDF samples have a much smaller permittivity than that of $\mathrm{P}(\mathrm{VDF}-\mathrm{TrFE})$ samples. Interestingly, these curves exhibit small amplitude dielectric relaxation around $1.5,4$, and $5 \mathrm{GHz}$ involving defects, bound charges, and polarized interfaces. (ii) As expected, $\varepsilon^{\prime}$ enhancement (up to $25 \%$ at $4 \mathrm{GHz}$ ) is observed as $\mathrm{GE}$ sheets are embedded in the amorphous phase of the pure polymer. The more pronounced increase in $\varepsilon^{\prime}$ is found for the copolymer sample with high melting point/high Curie temperature, i.e., $\mathrm{P}(\mathrm{VDF}-\mathrm{TrF})$ 77/23. (iii) These measurements also reveal very low dielectric losses due to the absence of free charge carriers.

Figure 4 presents results for $\left[\varepsilon^{\prime}(\lambda=1)-\varepsilon^{\prime}(\lambda>1)\right] /$ $\varepsilon^{\prime}(\lambda=1)$ as a function of the extension ratio $\lambda$ in strained samples at frequency set to $0.5 \mathrm{GHz}$. Remarkably, Fig. 4 illustrates a pronounced increase of permittivity (up to $13 \%$ at $0.5 \mathrm{GHz}$ ) for GE-filled copolymer samples which depends on the VDF content, while it decreases for the PVDF homopolymer filled with GE. It further appears that the permittivity spectrum of PVDF does not exhibit any change with strain up to $3.5 \%$. We note that the decreasing trend in this study is in line with previous microwave studies of polymers filled with a variety of filler nanoparticles, which was interpreted as due to the elasticity network of the polymer phase. In other words, the permittivity change is proportional to the Gaussian molecular network model (GMNM) functional form $\left(\lambda-\lambda^{-2}\right) \cdot{ }^{28}$ Simplistically, one might have expected that the application of the volume-conserving uniaxial deformation can be modeled phenomenologically by assuming that the elasticity network in the material occurs in a manner that is topologically similar to the elasticity network of a 


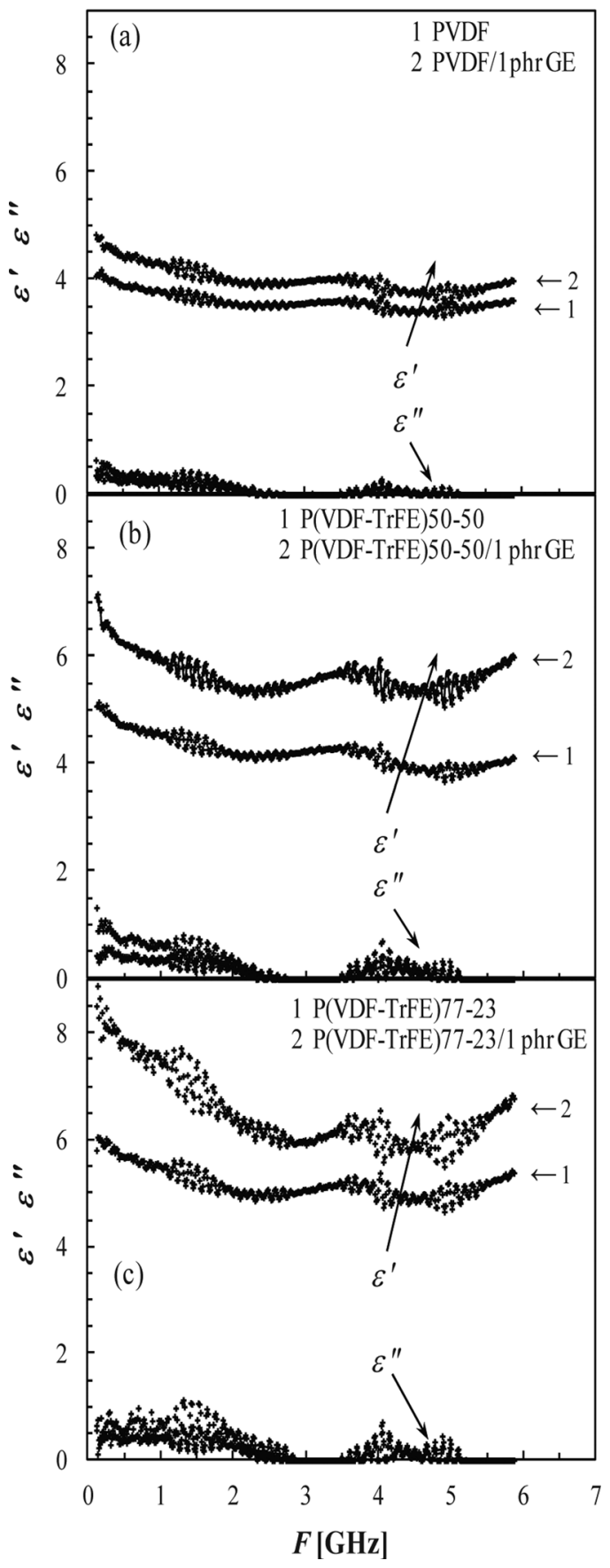

FIG. 3. (a) Room temperature effective permittivity vs frequency for unstrained samples PVDF without (red) or with (green) $1 \mathrm{phr}$ GE as indicated. (b) As in (a) for samples P(VDF-TrFE)50-50 without or with $1 \mathrm{phr}$ GE, as indicated. (c) As in (a) for samples P(VDF-TrFE)77-23 without or with $1 \mathrm{phr} \mathrm{GE}$, as indicated.

conventional rubber, i.e., assuming purely affine entropic stretching deformations.

The apparent contrast between GE-P(VDF-TrFE) copolymers and GE-PVDF homopolymer is perplexing. While the analysis to this point suggests that changes in the VDF content is important for understanding changes in permittivity, we conjecture that these permittivity enhancements at small loading depend significantly on the way the amorphous phase of $\mathrm{P}(\mathrm{VDF}-\mathrm{TrFE})$ interacts with the embedded GE nanoparticle surfaces. Qualitatively, this unexpected result is attributed to the enhanced interaction between trapped charges at the surface of the crystallites and molecular dipoles. The polarization

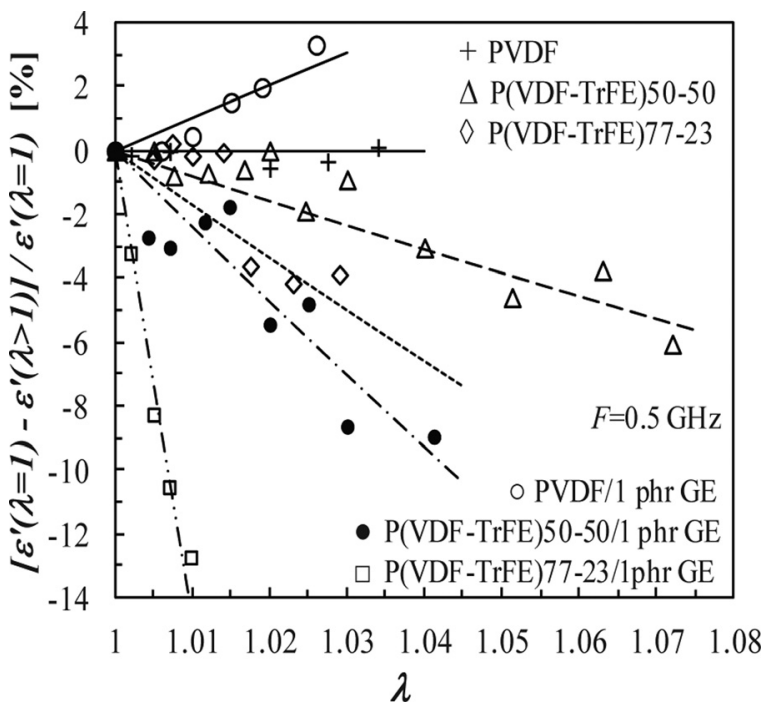

FIG. 4. Variations of $\left[\varepsilon^{\prime}(\lambda=1)-\varepsilon^{\prime}(\lambda>1)\right] / \varepsilon^{\prime}(\lambda=1)$ as a function of the extension ratio $\lambda$ in strained samples without or with $1 \mathrm{phr}$ GE at frequency set to $0.5 \mathrm{GHz}$. Room temperature. The best-fit curves (constrained to pass through the origin) to the GMNM functional form $\left(\lambda-\lambda^{-2}\right)$ are also shown.

of the copolymers is higher than pure PVDF because of the higher crystallinity of the copolymers. The copolymer sample with high melting point/high Curie temperature, i.e., $\mathrm{P}(\mathrm{VDF}-$ TrFE) $77 / 23$, is advantageous for facilitation of charge storage. We wish, further, to underscore that the increased permittivity observed through the electromechanical response of samples with TrFE reflects the release of these interfacial charges via charge hopping. The GE filled composites show larger permittivity enhancements (Fig. 4) because the presence of conductive high aspect ratio GE sheets creates low resistance pathways that allow interfacial charges to move to the material surface. In this regard, we note that a GE sheet is capable of withstanding reversible deformations of up to $10 \% .^{29}$

In summary, the distinguishing features of our analysis presented in this Letter are: (i) Our measurements quantify the microwave and mechanical properties of nanocomposites of GE sheets dispersed in $\mathrm{P}(\mathrm{VDF}-\mathrm{TrFE})$ for a variety of copolymer composition; (ii) for GE-P(VDF-TrFE) samples, an increase of permittivity is observed when the samples are uniaxially elongated which is noticeably different from samples containing only the PVDF homopolymer; (iii) these differences can be understood by accounting for changes in VDF content which affect crystallinity and, hence, the interaction of trapped charges and molecular dipoles, which is found to be beneficial to the electromechanical properties of GE-P(VDF-TrFE) samples. Such insights can be instrumental in further study of the physical phenomena at these interfaces. This Letter also raises several interesting questions. First, besides being an interesting model system to study how these semi-crystalline polymers with a piezoelectric and pyroelectric phase can be functionalized with GE sheets, the future direction of this project is to perform a careful and complete investigation of the GE-crystalline polymer phase interfaces by varying the GE particle loading, i.e., inter-sheet junction contact resistance of the GE sheets. Second, as physical ageing alters the physical properties of disordered solids and material lifetime to failure, it would be interesting 
to explore the characteristic features of the microwave properties of these samples under elongation, notably for actuation applications.

We thank G. Sinquin, B. Calvez, and F. Michaud for experimental assistance. The work of B. J. P. Adohi was made possible through the support of a Grant-in-Aid for Mobility from Université de Brest. The Lab-STICC is Unité Mixte de Recherche CNRS 6285.

${ }^{1}$ D. R. Smith, W. J. Padilla, D. C. Vier, S. C. Nemat-Nasser, and S. Schultz, Phys. Rev. Lett. 84, 4184 (2000); D. R. Smith, J. B. Pendry, and M. C. K. Wiltshire, Science 305, 788 (2004); D. Schurig, J. Mock, B. Justice, S. Cummer, J. B. Pendry, A. Starr, and D. R. Smith, ibid. 314, 977 (2006); R. A. Shelby, D. R. Smith, and S. Schultz, ibid. 292, 77 (2001); U. Leonhardt, Science 312, 1777 (2006); C. M. Soukoulis and M. Wegener, ibid. 330, 1633 (2010).

${ }^{2}$ A. Alú and N. Engheta, Phys. Rev. E 72, 016623 (2005).

${ }^{3}$ V. Castel and C. Brosseau, Appl. Phys. Lett. 92, 233110 (2008); V. Castel, C. Brosseau, and J. Ben Youssef, J. Appl. Phys. 106, 064312 (2009); V. Castel, M. Potel, and C. Brosseau, ibid. 108, 024306 (2010); P. Talbot, A.-M. Konn, and C. Brosseau, J. Magn. Magn. Mater. 249, 481 (2002).

${ }^{4}$ C. W. Nan, M. I. Bichurin, S. X. Dong, D. Viehland, and G. Srinivasan, J. Appl. Phys. 103, 031101 (2008).

${ }^{5}$ A. K. Geim and K. S. Novoselov, Nature Mater. 6, 183 (2007); A. C. H. Neto, F. Guinea, N. M. Peres, K. S. Novoselov, and A. K. Geim, Rev. Mod. Phys. 81, 109 (2009).

${ }^{6}$ S. Park and R. S. Suoff, Nat. Nanotechnol. 4, 217 (2009).

${ }^{7}$ D. Jin, A. Kumar, K. H. Fung, and N. X. Fang, Appl. Phys. Lett. 102, 201118 (2013).

${ }^{8}$ Z. Zhu, S. Joshi, S. Grover, and G. Moddel, J. Phys. D 46, 185101 (2013).

${ }^{9}$ Q. Cao and J. A. Rogers, Adv. Mater. 21, 29 (2009); J. A. Rogers, T. Someya, and Y. G. Huang, Science 327, 1603 (2010).

${ }^{10}$ C. Brosseau, Surf. Coat. Technol. 206, 753 (2011).

${ }^{11}$ S. Stankovich, D. A. Dikin, G. H. B. Dommett, K. M. Kohlhaas, E. J. Zimney, E. A. Stach, R. D. Piner, S. B. T. Nguyen, and R. S. Ruoff, Nature 442, 282 (2006)

${ }^{12}$ B. Das, K. E. Prasad, U. Ramamurty, and C. N. R. Rao, Nanotechnology 20, 125705 (2009).

${ }^{13}$ H. Kim, Y. Miura, and C. W. Macosko, Chem. Mater. 22, 3441 (2010).

${ }^{14}$ M. Hirata, T. Gotou, S. Horiuchi, M. Fujiwara, and M. Ohba, Carbon 42, 2929 (2004).

${ }^{15}$ J. R. Potts, O. Shankar, S. Murali, L. Du, and R. S. Ruoff, Compos. Sci. Technol. 74, 166 (2013).
${ }^{16}$ B. J. P. Adohi, D. Bychanok, B. Haidar, and C. Brosseau, Appl. Phys. Lett. 102, 072903 (2013).

${ }^{17}$ T. Ramanathan, A. A. Abdala, S. Stankovich, D. A. Dikin, M. HerreraAlonso, R. D. Piner, D. H. Adamson, H. C. Schniepp, X. Chen, R. S. Ruoff, S. T. Nguyen, I. A. Aksay, R. K. Prud'Homme, and L. C. Brinson, Nat. Nanotechnol. 3, 327 (2008).

${ }^{18}$ H. Kim, A. A. Abdala, and C. W. Macosko, Macromolecules 43, 6515 (2010).

${ }^{19}$ K.-K. Liao, ACS Nano 5, 1253 (2011); K.-H. Liao, ACS Appl. Mater. Interfaces 3, 2607 (2011); Polymer 53, 3756 (2012).

${ }^{20}$ T. Sharifi, E. Gracia-Espino, H. R. Barzegar, X. Jia, F. Nitze, G. Hu, P. Nordblad, C.-W. Tai, and T. Wågberg, Nat. Commun. 4, 2319 (2013); S. Ansari, A. Kelarakis, L. Estevez, and E. P. Giannelis, Small 6, 205 (2010); G. Eda, G. Fanchini, and M. Chhowalla, Nat. Nanotechnol. 3, 270 (2008); S.-H. Bae, O. Kahya, B. K. Sharma, J. Kwon, H.-J. Cho, B. Özyilmaz, and J.-H. Ahn, ACS Nano 7, 3130 (2013).

${ }^{21}$ L. Yang, S. L. Phua, C. L. Toh, L. Zhang, H. Ling, M. Chang, D. Zhou, Y. Dong, and X. Lu, RSC Adv. 3, 6377 (2013).

${ }^{22}$ Z. Chen, W. Ren, L. Gao, B. Liu, S. Pei, and H.-M. Cheng, Nature Mater. 10, 424 (2011).

${ }^{23}$ K. Tashiro, Ferroelectric Polymers: Chemistry, Physics, and Applications (Marcel Dekker, New York, 1995); M. E. Lines and A. M. Glass, Principles and Applications of Ferroelectrics and Related Materials (Clarendon Press, Oxford, 1977).

${ }^{24}$ B. J.-P. Adohi, A. Mdarhri, C. Prunier, B. Haidar, and C. Brosseau, J. Appl. Phys. 108, 074108 (2010).

${ }^{25}$ R. Gregorio, Jr. and M. M. Botta, J. Polymer Sci. Part B: Polym. Phys. 36, 408 (1998); E. B. Almaric and J. F. Legrand, Eur. Phys. J. 3, 225 (1998); S. Ansari and E. P. Giannelis, J. Polym. Sci., Part B: Polym. Phys. 47, 888 (2009).

${ }^{26}$ J. Buckley, P. Cebe, and D. Cherdack, Polymer 47, 2411 (2006); T.-H. Young, L.-P. Cheng, D.-J. Lin, L. Fane, and W.-Y. Chuang, ibid. 40, 5315 (1999).

${ }^{27}$ R. P. Chartoff, J. P. Menczel, and S. H. Dillman, "Dynamic mechanical analysis," in Dynamic Mechanical Analysis in Thermal Analysis of Polymers, 2nd ed., edited by J. D. Menczel and R. B. Prime (Wiley, New Jersey, 2009).

${ }^{28}$ C. Brosseau and P. Talbot, Meas. Sci. Technol. 16, 1823 (2005); P. Talbot, A. M. Konn, and C. Brosseau, J. Magn. Magn. Mater. 249, 483 (2002); C. Brosseau, W. Ndong, V. Castel, J. Ben Youssef, and A. Vidal, J. Appl. Phys. 102, 024907 (2007); C. Brosseau and W. Ndong, ibid. 104, 064108 (2008); C. Brosseau, W. Ndong, and A. Mdarhri, ibid. 104, 074907 (2008).

${ }^{29}$ V. M. Pereira, A. H. C. Neto, and N. M. R. Peres, Phys. Rev. B 80, 045401 (2009); R. M. Ribeiro, V. M. Pereira, N. M. R. Peres, P. R. Briddon, and A. H. C. Neto, New J. Phys. 11, 115002 (2009). 